Published online 2015 January 1.

Case Report

\title{
Ectopic Mediastinal Thyroid Tissue with a Normally Located Thyroid Gland
}

\author{
Mohamed Abdel Aal ${ }^{1}$; Fabian Scheer ${ }^{1}$; Reimer Andresen ${ }^{1, *}$ \\ ${ }^{1}$ Institute of Diagnostic and Interventional Radiology/Neuroradiology, West Kusten Klinikum Heide Academic Teaching Hospital, Universities of Kiel, Lubeck, Germany \\ ${ }^{*}$ Corresponding author: Reimer Andresen, Institute of Diagnostic and Interventional Radiology/Neuroradiology, West Kusten Klinikum Heide Academic Teaching Hospital, Universi- \\ ties of Kiel, Lubeck, Germany. Tel:+49-4817852401, Fax:+49-4817852409, E-mail: randresen@wkk-hei.de
}

Received: July 2, 2012; Revised: November 11, 2012; Accepted: December 16, 2012

\begin{abstract}
Ectopic thyroid tissue(ETT) is a rare entity and a challenging differential diagnosis. This is a report of a case of a mediastinal mass that was found to bean ectopic mediastinal thyroid tissue, in a 7 -year-old woman who was admitted to our hospital for breast cancer management. The mediastinal mass was identified in the postsurgical computed tomography (CT) scan of the chest and was suspected as mediastinal lymph node metastasis. A CT-guided percutaneous transthoracic punch biopsy (CT-TPB) proved to be an adequate diagnostic tool to exclude malignancy and provide a definite diagnosis of the mediastinal mass. We find that CT-guided punch biopsy as a useful diagnostic alternative enabling histopathological specimens to be obtained from mediastinal masses and lymph nodes suspected of malignancy.
\end{abstract}

Keywords: Ectopic; Thyroid Gland; Mediastinum

\section{Introduction}

Ectopic thyroid tissue (ETT) is a rare finding that composes approximately $1 \%$ of mediastinal tumors (1). ETT could be found anywhere along the path of initial embryologic descent of the thyroid gland from the floor of the primitive foregut to its normal pre-tracheal position (2). Ninety percent of all ectopic thyroid tissues are found along this path of decent, whereas about $10 \%$ have been found in other anatomical locations including the mediastinum and the heart $(2,3)$.

\section{Case Presentation}

A 77-year-old woman with a left breast tumor underwent radical mastectomy with axillary lymph nodes dissection. Pathological examination of the resected tumor revealed invasive ductal carcinoma without node metastasis. The patient was presented to our radiology department for pre- and post-surgical diagnostic procedures. In the pre-surgical chest X-ray, there was an abnormal well-defined density in the left paratracheal region above the aortic arc with deviation of the trachea to the right
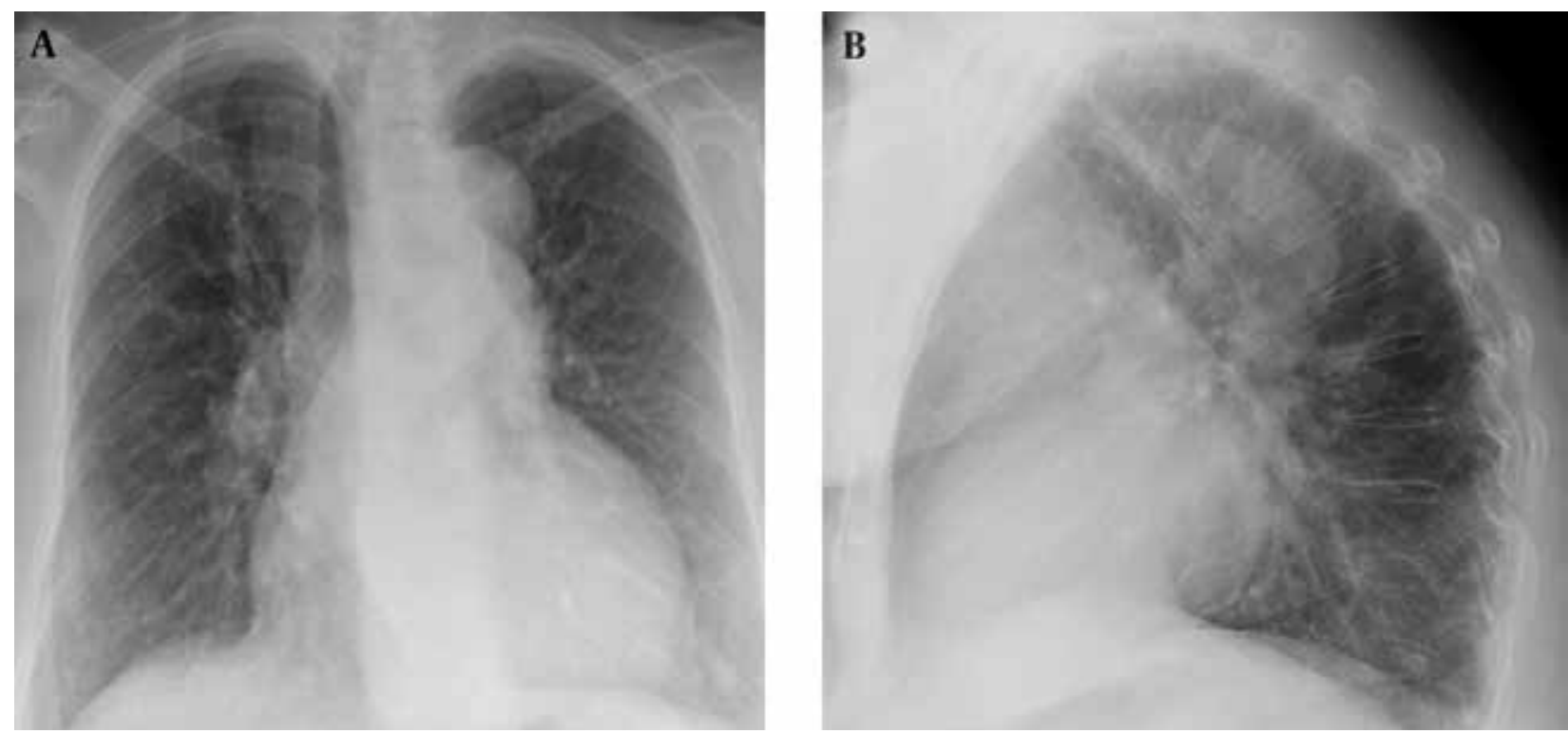

Figure 1. A 77-year-old woman with breast cancer and an abnormal well-defined density in the left paratracheal region. A, Posteroanterior and B, Lateral chest X-rays

Copyright (C) 2015, Tehran University of Medical Sciences and Iranian Society of Radiology. This is an open-access article distributed under the terms of the Creative Commons Attribution-NonCommercial 4.0 International License (http://creativecommons.org/licenses/by-nc/4.0/) which permits copy and redistribute the material just in noncommercial usages, provided the original work is properly cited. 
(Figure 1). A postoperative contrast-enhanced chest CT scan was performed as part of staging workup. The scan demonstrated round, hypodense nodular changes in the parenchyma of the left lobe of the thyroid gland (Figure 2). This finding was further investigated with ultrasonography and was consistent with a thyroid cyst.

The CT scan also revealed a large anterior mediastinal mass $70 \times 58 \times 55 \mathrm{~mm}$ in size on the left side of the aortic arch. The mass was not in direct continuity with the normally located pretracheal thyroid gland (Figure $2 \mathrm{E}$ and F). It showed heterogeneous contrast enhancement of the ETT mass which is not in direct continuation with the nor- mally located thyroid gland (Figure 3 A and B). Such masses are highly suspicious for lymph node metastasis and require further investigation. Subsequently, the patient was subjected to a Tc-99m-HDP bone scan that showed no evidence of bone metastasis. The mass was then biopsied with a semi-automated core biopsy system (G 16) under CT guidance (Figure $3 \mathrm{C}$ ) for histopathological evaluation. A total of 5 core biopsies were taken from different parts of the mediastinal mass. The histopathological examination of the biopsy revealed normal thyroid parenchyma (Figure 4). The functional thyroid parameters such as thyroid stimulating hormone(TSH) were within the normal levels.
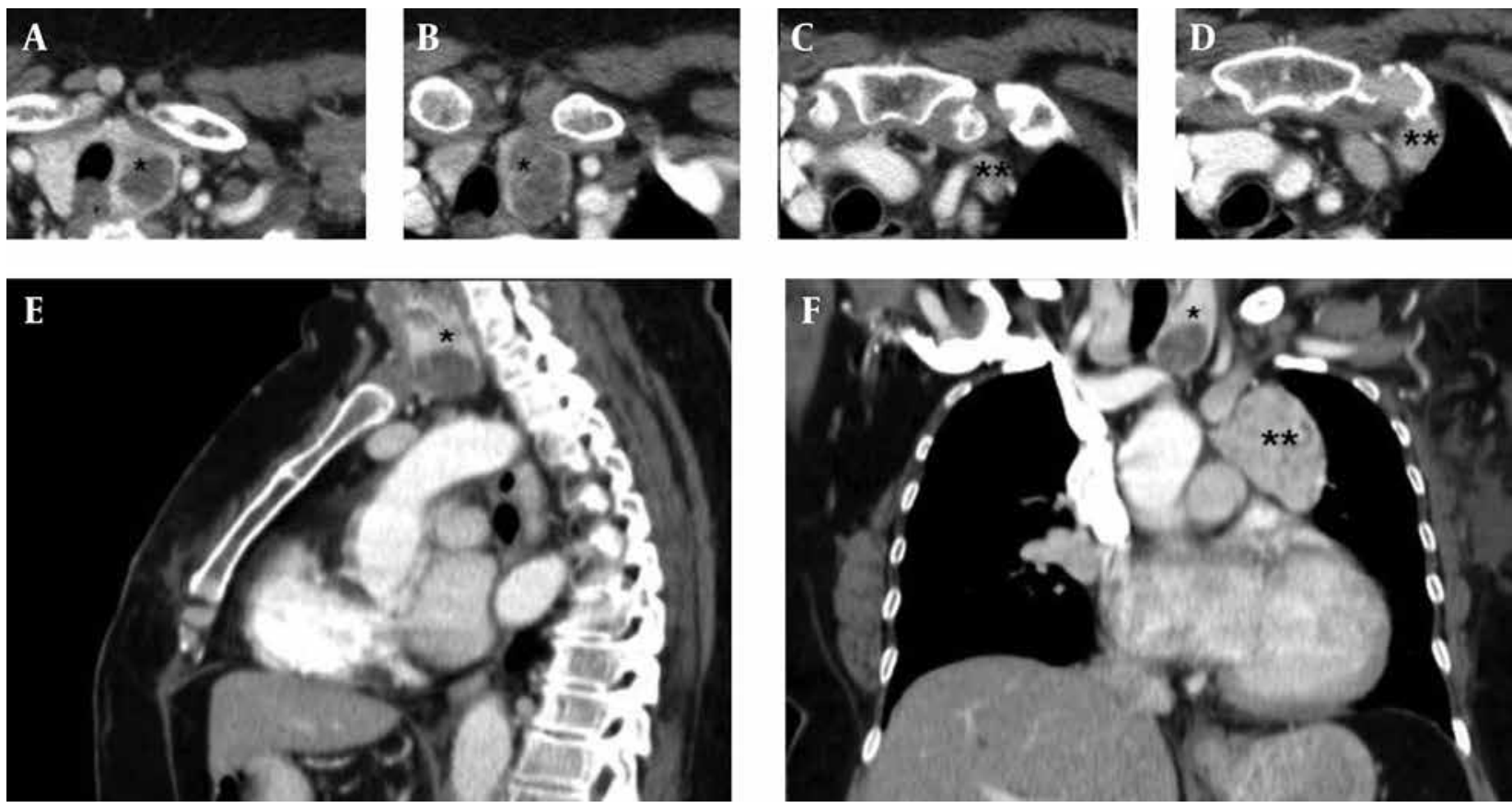

Figure 2. CT scan of the neck and chest, A-D, Axial view, E, Sagittal view, F, Coronal view. CT scan of the neck and chest shows a normally located thyroid gland $\left({ }^{*}\right)$ and the distinct location of the ETT $\left({ }^{* *}\right)$.
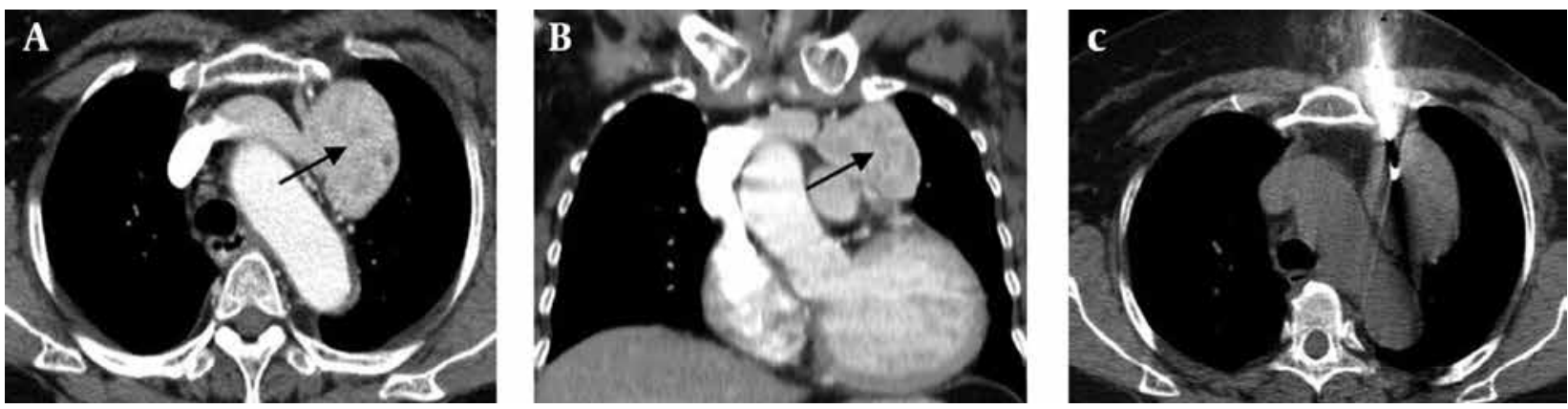

Figure 3. CT scan demonstrates a large anterior mediastinal mass on the left side of the aortic arch (arrow). A, Axial view; B, Coronal view; C, Axial CT images taken during the CT-guided punch biopsy procedure show the path of the semi-automated biopsy system. 


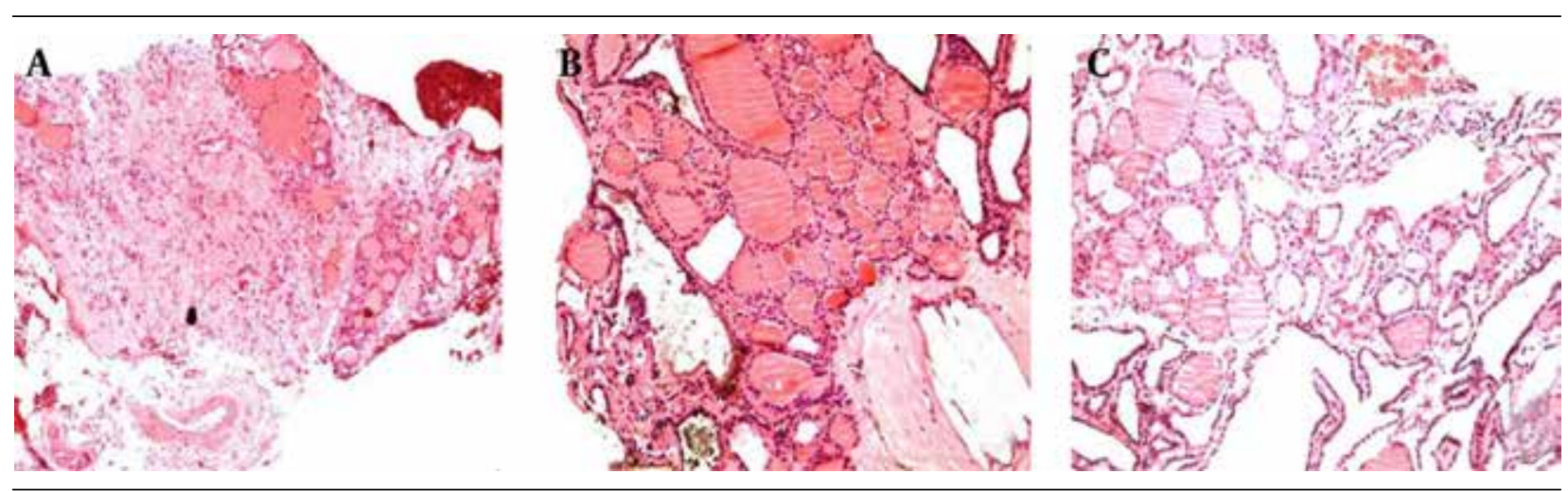

Figure 4. A, Low-power view of the biopsy specimen demonstrating normal thyroid tissue (H \& E, original magnification 30×, B and C, High-power view reveals a normally appearing thyroid follicular epithelium filled with colloid material ( $\mathrm{H} \&$ E original magnification 200×)

\section{Discussion}

ETT is defined as thyroid tissue not located anterolaterally to the second to fourth tracheal cartilages. Lingual thyroid is the most common form of thyroid ectopy, accounting for $90 \%$ of the reported cases (4). Other rare sites of an ectopic thyroid gland include the mediastinum, esophagus, lung, heart, aorta and abdomen (4).

The thyroid gland is the first of the body's endocrine glands to develop. The gland originates as a proliferation of endodermal epithelial cells on the median surface of the developing pharyngeal floor. The gland then migrates to reach its final location immediately anterior to the trachea. During the process of migration, the thyroid remains connected to the tongue by the thyroglossal duct. The descent of the thyroid gland occurs anterior to the hyoid bone and anterior to the laryngeal cartilages. As the thyroid gland descends, it gradually forms its mature shape, with a median isthmus connecting the two lateral lobes. The thyroid completes its descent in the seventh gestational week.

Presence of ectopic thyroid tissues in distant locations could happen as a result of abnormal migration or heterotopic differentiation of uncommitted endodermal cells (5). It has been suggested that an over descent of thyroglossal duct remnants is the cause of ectopic thyroid tissue in the mediastinum (6).

In this case report, we described a patient who had invasive ductal carcinoma of the breast. The patient was euthyroid at presentation and did not have any symptoms related to a mediastinal mass such as dyspnea, cough, mediastinal obstruction or compression symptoms. Even though the preoperative chest X-ray provided a clue for a mediastinal soft tissue mass, radical mastectomy was still indicated. Mediastinal ETT cannot be differentiated based on chest X-ray alone. The postoperative CT of the chest provided more information about the location of the mediastinal mass and its association to the great vessels and other mediastinal structures. Due to the given history of our patient, mediastinal metastasis from the breast cancer was at the top of our list of differentials.
According to Rampado et al. (autoptic study), the incidence of mediastinal and esophageal metastasis ranges between 5\% and 6\% among women dying of advanced breast cancer (7).

A thyroid mass usually demonstrates high CT density on plain scan due to the iodine content as well as intense and sustained intravenous contrast enhancement (8). In non-enhanced CT, the thyroid is not usually mistaken for a lymph node because of its higher density. Due to the history of malignant tumor in our patient, mediastinal lymph node involvement was suspected. A core biopsy via a semi-automated system under CT guidance accounted for safety and good tissue specimen integrity that provided us with a definite histopathological diagnosis. In contrast to mediastinoscopy with biopsy and exploratory surgery, CT-guided punch biopsy does not require general anesthesia and it is less invasive. Scintigraphy offers a useful and effective alternative to differentiate ETT from other mediastinal tumors. In case of positive I-131 scintigraphy, ETT will be among the list of possible differential diagnoses. However, scintigraphy can be considered as a diagnostic test only when ETT has to be suspected first. It is also important to note that the uptake of I-131 is not always observed in ETT; therefore, scintigraphy is not always diagnostic (9). In contrast to retrosternal goiter or secondary intrathoracic goiter, true ETT receives its blood supply from the mediastinal vessels rather than the neck vessels (9). In this patient, the ETT mass is not in direct continuation with the normally located thyroid gland (Figure $3 \mathrm{~A}$ and $\mathrm{B}$ ).

Generally, malignant transformation in ETT is very rare (10). Nevertheless, these masses should be resected surgically due to the risks of malignant transformation, progressive enlargement, hemorrhage within the mass causing respiratory failure and compression of neighboring vital mediastinal organs. If the patient decides to refuse the surgical treatment, frequent monitoring will be recommended in order to detect any early signs or symptoms of thyroid dysfunction or malignant transformation. 
Although ETT is rare, physicians should consider the possibility that mediastinal ETT could be a differential diagnosis of a mediastinal mass. Differentiating ETT from other mediastinal masses is extremely important because the diagnosis affects management and outcome. Some of the important differential diagnoses of anterior mediastinal mass include thymic tumors, lymphomas and dermoid cysts. Awareness of the possibility of the existence of normal and maybe functional thyroid tissue is necessary before planning surgical removal, chemotherapy or radiation therapy. Due to the growing number of reports on ectopic thyroid and ETT, we find that CT-guided punch biopsy as a useful diagnostic alternative enabling histopathological specimens to be obtained from mediastinal masses and lymph nodes suspected of malignancy.

\section{References}

1. Sakorafas GH, Vlachos A, Tolumis G, Kassaras GA, Anagnostopoulos GK, Gorgogiannis D. Ectopic intrathoracic thyroid: case report. Mt Sinai J Med. 2004;71(2):131-3.

2. Babazade F, Mortazavi H, Jalalian H, Shahvali E. Thyroid tissue as a submandibular mass: a case report. J Oral Sci. 2009;51(4):655-7.

3. Gallo A, Leonetti F, Torri E, Manciocco V, Simonelli M, DeVincentiis M. Ectopic lingual thyroid as unusual cause of severe dysphagia. Dysphagia. 2001;16(3):220-3.

4. Choi JY, Kim JH. A case of an ectopic thyroid gland at the lateral neck masquerading as a metastatic papillary thyroid carcinoma. J Korean Med Sci. 2008;23(3):548-50.

5. Ghanem N, Bley T, Altehoefer C, Hogerle S, Langer M. Ectopic thyroid gland in the porta hepatis and lingua. Thyroid. 2003;13(5):503-7.

6. Harach HR. Ectopic thyroid tissue adjacent to the gallbladder. Histopathology. 1998;32(1):90-1.

7. Rampado S, Ruol A, Guido M, Zaninotto G, Battaglia G, Costantini $\mathrm{M}$, et al. Mediastinal carcinosis involving the esophagus in breast cancer: the "breast-esophagus" syndrome: report on 25 cases and guidelines for diagnosis and treatment. Ann Surg. 2007;246(2):316-22.

8. Lau S, Yeung WH, Kwan WH, Cheng CS, Lam HS. Computed tomography of anterior mediastinal masses. J HK Coll Radiol. 2003;6(2):100-6.

9. Barbetakis N, Chnaris A, Papoulidis P, Siobolas P, Kostopoulos G Ectopic Mediastinal Thyroid Gland. A Case Report and Review of the Literature. Hosp Chronicles. 2010;5(2):99-102.

10. Shah BC, Ravichand CS, Juluri S, Agarwal A, Pramesh CS, Mistry RC. Ectopic thyroid cancer. Ann Thorac Cardiovasc Surg. 2007;13(2):122-4. 